\title{
Children Playing and Learning: Crafting Ceramics in Ancient Indor Khera
}

\author{
(Q) (2) (Q) \\ JAYA MENON AND SUPRIYA VARMA
}

\section{INTRODUCTION}

SEVERAL YEARS AGO WHEN WE WERE WRITING CHAPTERS for ancient Indian history school textbooks, a colleague asked if there was any archaeological evidence on children that could be included in these chapters. We thought hard but were unable to come up with any archaeological work that actively engaged with children in ancient India. We wondered why there was no work and realized that we ourselves had actually thought little about the issue until then. In the summer of 2007, while we were excavating at the ancient site of Indor Khera, we started finding miniature vessels and began to speculate as to who could have made them. Several months later when we began a more detailed study of terracotta finds, the attributes of these miniature vessels suggested to us that these could have been made by children. In trying to substantiate this hypothesis we undertook the exercise to see how children as "novice crafters" (taken from Baxter 2008) had been studied elsewhere.

It is only in the last decade that a considerable body of research has focused on children through material culture. Interest in children has to an extent emerged as an offshoot of studies on gender and archaeology, the latter itself having received attention only within the last two decades. Some of the ways that children have been made visible by archaeologists is through representation, bioarchaeological data, and the identification of some miniature objects as toys. Among the several themes that have been investigated are identifying stages of childhood, aspects of health and nutrition, child raising practices, socialization into adult roles, learning, children at work, and the meaning of childhood (Ardren 2006; Ardren and Hutson 2006; Baxter 2005, 2006, 2008; Kamp 2001a, 2001b, 2002, 2006; Kamp et al. 1999; Park 1998, 2006; Smith 2006). ${ }^{1}$

Often, miniature objects are associated with children as toys, which may or may not always be valid. Miniature objects can be used in other ways, such as grave offerings, as ritual and votive artifacts, or as containers for unguents and 
pigments (Baxter 2005:47-48; Park 1998, 2006). The term "miniature" itself has been debated, with one definition being "a smaller version of another object differentiated only by size and often the resulting lack of a commensurate function with the larger object" (Baxter 2005 : 47). However, another study discusses how miniature forms could serve the same purpose as full-sized objects (Park 2006). It has also been reiterated that small objects that do not have larger size counterparts should not be categorized as miniatures (Baxter 2005). Yet, rather than limiting the term miniature to smaller reproductions alone, we feel that it can be extended to the smallest in a range of sizes even when they are not imitations of full-sized ones. This could well be the case with a craft working area wherein we may find vessels of different sizes that may represent learning stages within the ceramic craft (Kamp 2001b).

Much of the work that has been initiated on gender and children has not found resonance so far within South Asian archaeology, although some issues of gender, particularly through representation in the form of Harappan terracotta human figurines, have had nuanced readings (Clark 2003). Archaeologically, infants and children are visible directly through burials. Raczek's (2003) study of burials in the context of the late Deccan Chalcolithic suggests that while the practice of infant burials continued throughout at Inamgaon from Malwa to Late Jorwe (1600-700 B.C.), at other sites it was not the case. The persistence of infant burials at Inamgaon has been suggested to indicate the need of families to uphold certain traditions in the face of considerable subsistence and societal changes. However, at the other late Deccan Chalcolithic sites such as Chandoli, Daimabad, Nevasa, Songaon, and Walki, burial practices for infants and children were probably following those of adults, where either burials were located offsite or what may instead have been practiced were exposure of bodies or cremation combined with the immersion of ashes in the nearby river. More indirectly, the presence of children has been visualized through toys. Practically every excavation report of Neolithic, Chalcolithic, Bronze Age, and Iron Age sites in the subcontinent includes categories of artifacts that are invariably interpreted as children's toys such as marbles, "toycarts," "hopscotches," 2 and so forth. However, children have rarely been considered active agents in the production of material culture. There is little discussion about the way toys would have been used by children, the spaces/places of children's activities, as well as how these would have impacted the distribution patterns of artifacts in general.

In the context of children, two particular aspects will be explored here based on the evidence from the site of Indor Khera in the Upper Ganga Plains in India, which is being currently excavated by the authors. This article, framed in three parts, will deal with learning frameworks within craft production and the social spaces specific to children's activities and things. The first section will discuss some of the archaeological work that has been done on children as learners in craft. In the second section, we will sketch out the excavations in a particular part of the mound of Indor Khera where deposits from between 200 B.C. and A.D. 300 were exposed. The basis for this chronological frame will be referred to as well as the evidence for houses and terracotta finds from this area. This in turn has allowed us to elucidate children's activities, spaces, and learning patterns within ceramic manufacture, which is dealt with in the final section. 


\section{CHILDREN AS NOVICE CRAFTERS}

One of the promising areas for studying children in archaeology has been through craft working. Largely, the discussion in this section will focus on the ceramic craft; compared to other crafts, much more archaeological, ethnoarchaeological, and ethnographic work has been done on ceramics. Moreover, this particular craft is also directly relevant for our study. It is well recognized that craft knowledge and traditions are transmitted from one generation to the next. This would be the case with productions both in workshop situations as well as that taking place at the household level where craft techniques would be disseminated from master crafters to apprentices. It is in both contexts that children as learners and novice crafters become significant.

Largely, there are two major mechanisms of learning a craft. One comprises the imparting of formal verbal instructions and demonstrations while the other consists of observation and imitation (Kamp 2001b). Early stages of learning may also start with auxiliary activities in the craft. When most ceramic production, for example, takes place within the house, one sees the involvement of the potter's family, including women and young children, who help with the decoration of unglazed ware and other tasks such as preparing clay, carrying, and shifting vessels at various stages of the manufacturing process (Kamp 2002:28; Rye and Evans 1990 : 168). Several ethnographic studies in South Asia focusing on ceramic production at the household level concentrate on the male crafter with women and children performing the subordinate but necessary tasks such as clay procurement and preparation, decorating finished vessels, and so forth. Often, when molding of vessels is required, this is a task that is done by women (Roux and Corbetta 1989:8). Similarly, the molding of ceramic figurines is a technology that would have permitted crafters of various ages, including children, to participate in their production (Lopiparo 2006:169). A specific case study on apprenticeship in ceramic manufacture focusing on the stages by which small boys began to use the wheel for making ceramics found that boys began learning between the ages of eight and eleven, due to the physiological reason of being able to reach the center of the wheel by then. However, they were actively helping in the craft even in early childhood with clay preparation, beating operations, and moving the pots during the drying process (Roux and Corbetta 1989:10).

It has also been suggested that "craft learning may be sequential, starting with easier forms then proceeding to more complex, may occur in quite unstructured contexts, apparently viewed to some extent as play, and may start in the guise of fun at a young age" (Kamp 2001b:430). It is possible that children as young as two to five years old could start the learning process (Kamp 2001a: 13). While many of the aspects regarding learning processes may not be visible in material culture, what in fact may be identifiable are artifacts made by beginners in that particular craft. While the role of children in ceramic manufacturing, stone tool knapping and weaving has been studied, relatively much more work has been done in relation to ceramics. We have found the studies by Kamp (2001a, $2001 b$ ) and Kamp et al. (1999) to be particularly useful in identifying novices in ceramic manufacture at Indor Khera and which need to be discussed in some detail. 
A reasonable assertion has been made that since novices may not have the requisite conceptual knowledge or motor skills for ceramic production, this may then result in imperfect products or unusual forms or decoration. Novices may perhaps be unable to make large, regular, or evenly walled vessels. Lack of mastery by beginners in the techniques of clay preparation and tempering, drying, and firing may also show up in some of the end products. Several criteria have been listed to illustrate the difference in skills between novices and experts. Small size of vessels, the pinch pot technique, asymmetry in vessel profiles, uneven thickness of vessel walls, rough finish, and small drying cracks may be associated with novices. In contrast, large vessels, well-coiled or beaten vessels, symmetry of vessel profiles, even wall thicknesses, smoothened and burnished surfaces, and lack of cracks suggest the work of experts (Kamp 2001b:430-431).

Similarly, the products of novices may differ in shape from those usually manufactured. These may reflect the lack of internalization of cultural expectations or incomplete "conceptual mastery of style forms or principles." The products of learners may show a lack of access to high-quality raw materials or the technological inability to process the raw materials. It is also important to realize that while children learning a craft would be beginners, not necessarily all novices are children. Further, identifying the gender of beginners may be difficult in the archaeological record.

The age of crafters may be problematic but is possible to assess archaeologically. Kamp (2001b) has pointed out that certain errors may be age related, such as inexpert workmanship, inadequate sealing of coils, and asymmetry of designs. Another way by which the age of crafters can be assessed is from the fingerprints left on ceramics and terracotta figurines. Kamp shows that with age, because the surface area of the finger expands, this can be measured through ridge breadth measurements, defined as "the width of a single ridge and valley pair." Her study involved an experimental work conducted on individuals of different ages to investigate the relationship between ridge breadth and age (Kamp 2001b; Kamp et al. 1999). Several criteria were then used to ascertain the age of producers of ceramics and terracotta figurines dated between A.D. 1100-1250 from the Sinagua region of northern Arizona (Kamp 2001b:434-447). The parameters of small size, crudeness and lumpiness, inexpert workmanship as seen from lack of surface smoothness, the presence of fingerprints and nail marks, asymmetrical profiles, and lack of proportion and missing limbs for animal figurines were used in the case of figurines.

As far as ceramics are concerned, size variation was used as one criterion to distinguish three categories of full-size, small size, and miniature vessels. Other criteria used were cracks, finishes, rim and wall thicknesses, as well as fingerprint measurements. Full-sized vessels indicate the work of experts as listed above. In contrast, miniatures suggest the work of novices, particularly when combined with characteristics of low-skilled work. Small-sized vessels showed a bit of both high-quality and low-quality workmanship. These may suggest a gradual process of learning from miniature to small to large vessels. Thus, figurines and miniature vessels served as toys as well as steps to initiate children into technical processes of working with clay, such as adding tempering materials, shaping vessels and figurines, drying them, and firing. Adults may also have assisted with some of these steps, particularly with firing. 
Most archaeologists agree with the criteria, such as small size, and imperfect forms and decorations, which have been used to identify the work of children. An interesting point raised by Smith (2006) is that deviations from the norm in decorations need not necessarily imply a lack of conceptual mastery, but may in fact reflect innovation on the part of children. Her argument is that children as learners, when introducing innovations in decorative motifs, should not be viewed as passive imitators, but as active participants in the learning process. In her study of the prehistoric matrilineal Huron society in Canada, Smith (2006:71) suggested that while children would have learned from their mothers and grandmothers, they also influenced each other. Kamp (2001a:27) has also made the point that children can learn from other children.

Children as innovators can also be seen ethnographically in the craft of weaving, as in the case of the Maya community in Honduras, from the 1970s to the 1990s. Often with larger societal changes, such as incorporation into a market economy, shifts can take place in learning frameworks, from being highly supervised and focusing on replication to crafting more or less independently and through trial and error. The shift was thus from conservatism in designs and techniques to innovation (Baxter 2008:168-169).

Other crafts where children have been identified as learners include lithic production and weaving. The evidence of poor-quality worked flint pebbles found alongside fine blade production suggests the presence of crafters of varying abilities. Archaeological evidence for novice lithic crafters can be seen from the locations of craft where poorly worked lithics are found peripheral to the work of master crafters and from the use of poor-quality raw materials. Often, the work of inexpert knappers does not result in usable tools (Baxter 2008:168). Thus, the products of beginners may be identified as those that show inexpert craftwork or deficiencies in manufacture, are often small in size, use simple techniques and poor-quality raw materials, show variability or a lack of standardization, and may skip certain technological steps.

This discussion has shown the potential of searching for children in the context of craft working. While much archaeological as well as experimental and ethnoarchaeological work has been done in South Asia, on techniques, locations of craft, as well as the issue of specialization, this has mainly been done in the context of Harappan craft. For other periods, much less work on craft is available and what is striking is that children themselves have so far remained invisible. In this context, the excavations at Indor Khera have provided an opportunity to initiate studies on locating children in craftwork. In the following section, an overview of recent excavations at Indor Khera is given, so as to contextualize children as learners in ceramic manufacture.

\section{INDOR KHERA}

The excavations undertaken at Indor Khera in the summer of 2007 will be discussed in this section. Summary information on the site, its location, the chronology, and the evidence in the form of structures and terracotta finds will be presented. However, a more detailed discussion can be seen in Varma and Menon (n.d.). The discovery of craft quarters at the northwestern edge of this settlement, 


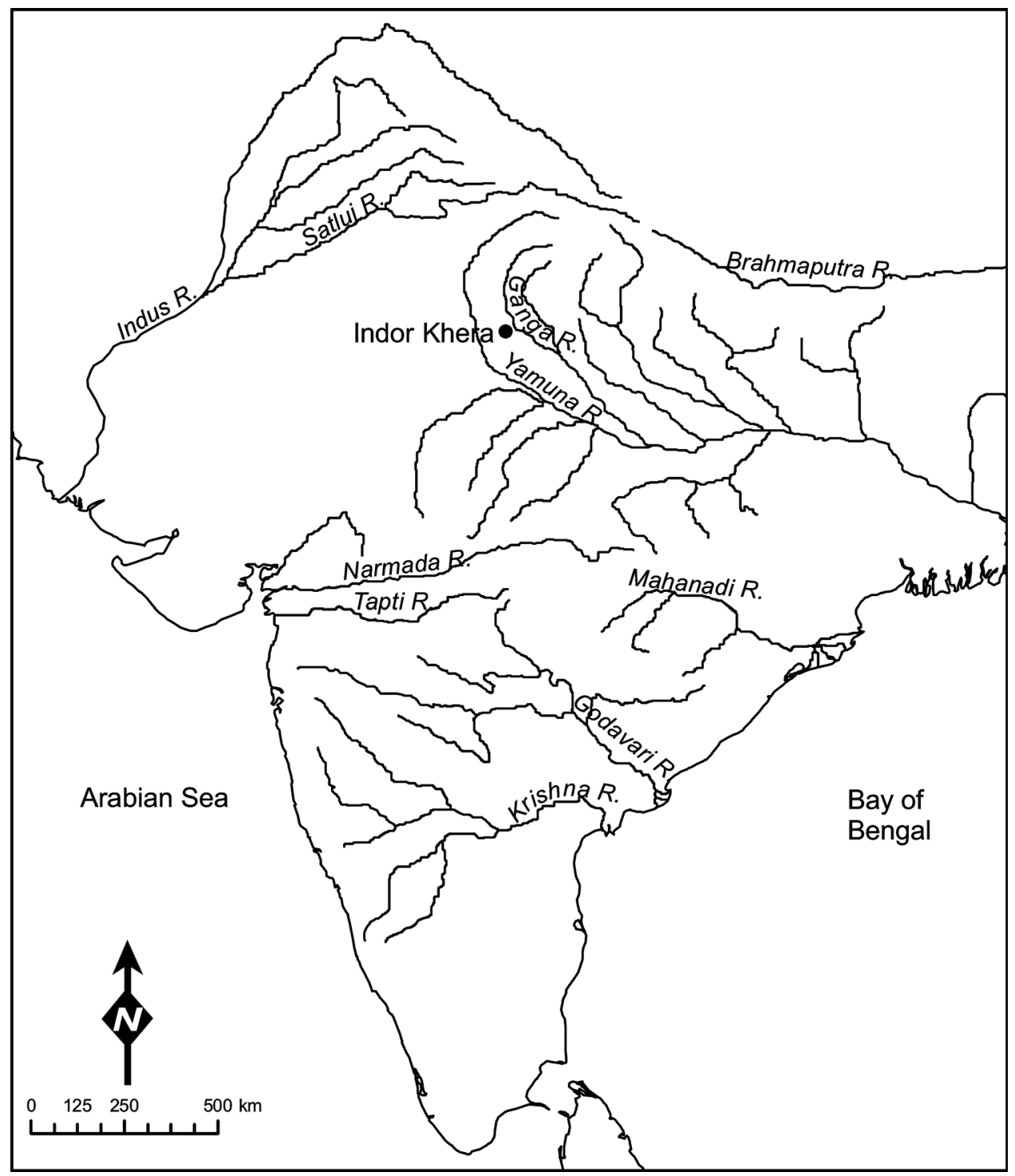

Fig. 1. Location of Indor Khera.

in particular a potter's house, and different phases of domestic architecture comprise important evidence for the period dated between 200 B.C. and A.D. 300.

The site of Indor Khera $\left(28^{\circ} 14^{\prime} 57^{\prime \prime} \mathrm{N}, 78^{\circ} 12^{\prime} 48^{\prime \prime} \mathrm{E}\right)$ is located in Tehsil Debai, District Bulandshahr, Uttar Pradesh on the Chhoiya Nadi, also called Nim Nadi. Indor Khera lies between the rivers Kali Nadi and Ganges (Fig. 1). The site is about $10 \mathrm{~km}$ from the Ganges River. The mound measures $285 \mathrm{~m}$ (northsouth) $\times 428 \mathrm{~m}$ (east-west) with a maximum height of $17 \mathrm{~m}$, with the presentday village of Indor extending over the entire eastern, northwestern, and southeastern portions of the mound and the adjacent area. 
Trial soundings taken at the site of Indor Khera indicated the potential for further excavation. Two of the trial cuttings gave us tentative dates from the tenth/ eleventh to the thirteenth/fourteenth centuries A.D., while the third sounding was dated from 1000 B.C. to A.D. 100 (Menon et al. 2008; Menon and Varma n.d.). It is important to note that this apparent gap between A.D. 100 and the tenth century A.D. was not due to a break in occupation, but because the intervening periods have so far not been investigated. The intention, thus, was to excavate in an area that would enable us to bridge this gap. For this reason, we chose the northwestern area of Indor Khera where there is a flat exposed ridge halfway down the slope of the mound. This ridge has been created by the cutting away of the mound in this area by local villagers.

As mentioned in an earlier article (Menon et al. 2008), exposed fortification walls particularly in the northern, eastern, and southern parts of the mound are visible today. The fortification walls were made of baked bricks, with dimensions ranging from $38-43 \times 22-23 \times 5.5-6 \mathrm{~cm}$. In the eastern part of the mound, the walls are comprised of an inner and an outer wall, with cross-walls. However, in the other parts of the mound, only one wall with cross-walls or revetments has been observed. Just north of this ridge and about $2 \mathrm{~m}$ lower, an exposed fortification wall and cross-walls are visible in an adjacent house. Given the alignment of the exposed walls, we expected these fortification walls to continue southward, that is, in the area of the ridge. Excavation squares were, thus, laid in such a way so as to get an idea of the occupation deposits both inside and outside the fortifications.

As the area under the present village was not going to be excavated, only the unoccupied parts of the site were gridded on a $10 \times 10 \mathrm{~m}$ grid. The layout of squares followed this grid. As can be seen from Figure 2, the northernmost point on the north-south reference line is G0. This also marked the southern limit of the present-day village in this part of the mound. South of G0, each consecutive east-west row of $10 \times 10 \mathrm{~m}$ squares was labeled as A, B, C, and so forth. In turn, the squares to the west of the north-south reference line were labeled as A1, A2, A3, A4, and so forth. Those squares to the east of the reference line were labeled as ZA1, ZA2, and so forth. Each $10 \times 10 \mathrm{~m}$ square was subdivided into four subsquares of $5 \times 5 \mathrm{~m}$, with a cutting area of $4 \times 4 \mathrm{~m}$ each. These subdivisions were in turn labeled. For example, the $10 \times 10 \mathrm{~m}$ square B1 had four $5 \times 5 \mathrm{~m}$ subsquares, labeled as B1a, B1b, B1c, and B1d, with B1a as the northwest subsquare and the others following in a clockwise direction.

The following squares and subsquares were excavated in this area: A1d, B1a, $\mathrm{B} 1 \mathrm{~b}, \mathrm{~B} 1 \mathrm{c}, \mathrm{B} 1 \mathrm{~d}, \mathrm{~B} 2 \mathrm{~b}, \mathrm{~B} 2 \mathrm{c}, \mathrm{C} 1 \mathrm{a}, \mathrm{C} 2 \mathrm{a}$, and $\mathrm{C} 2 \mathrm{~b}$. The reason why in some places only parts of subsquares could be opened was due to the encircling ridge or the edge of the mound. Hence, the cutting areas of A1d, B1b, B1c, B2b, and B2c were $4 \times 2 \mathrm{~m}$, while the subsquares had a cutting area of $4 \times 4 \mathrm{~m}$ (Fig. 2). The excavations were carried out to varying depths: A1d to $40 \mathrm{~cm} ; \mathrm{B} 1 \mathrm{a}, \mathrm{B} 1 \mathrm{c}$, and $\mathrm{B} 1 \mathrm{~d}$ to $176 \mathrm{~cm}$; B1b to $115 \mathrm{~cm} ; \mathrm{B} 2 \mathrm{~b}$ to $52 \mathrm{~cm} ; \mathrm{B} 2 \mathrm{c}$ to $60 \mathrm{~cm}$; $\mathrm{C} 1 \mathrm{a}$ to $60 \mathrm{~cm}$; $\mathrm{C} 2 \mathrm{a}$ to $50 \mathrm{~cm}$; and $\mathrm{C} 2 \mathrm{~b}$ to $60 \mathrm{~cm}$.

\section{Chronology}

We were able to date the deposits in these trenches on the basis of pottery and coins. From square B1 were found stamped potsherds, sprinkler forms, tiny sherds of wares with a black slip or polish and a red core, and sherds of fine gray ware. 


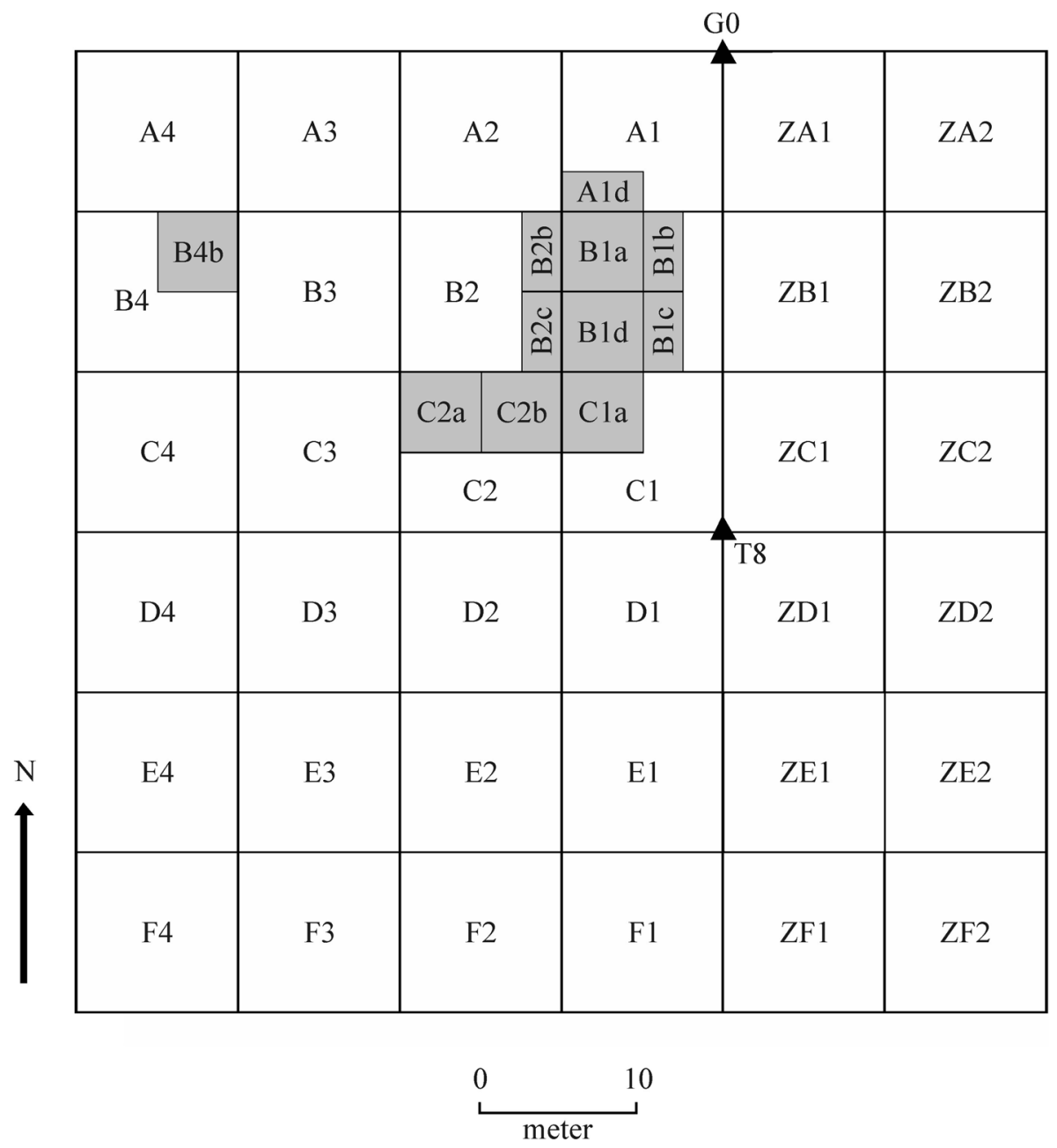

Fig. 2. Layout of excavated squares at Indor Khera.

The bulk of the pottery comprised red wares. Also excavated from this square were two terracotta stamps used for decorating pottery.

Out of a total of seven copper coins recovered, three coins are datable to the Kushana period, three are entirely unreadable, while the last is a square punchmarked coin. A coin from the reign of Huvishka was excavated from subsquare B1b. From the same subsquare and depth was found a coin with part of the dotted flan still visible but the rest was unclear. Three coins, stuck together, came from subsquare C2a, but only one was well preserved. This is a coin of Vima Kadphises, showing the king on the obverse standing with his head turned to his right, offering his right hand to an altar and on the reverse is a figure of a bull. This is similar to the gold coin illustrated by Gupta (1996: Plate VII, 64, Plate VI, 62). Another Kushana coin with the king on the obverse with part of a Greek legend still visible, and a completely mineralized reverse side was recovered from the same subsquare and depth. The copper punch-marked coin was found in Square B1c. 
While the Kushana copper coins were found from the upper deposits, the few sherds with black slip or polish and the copper punch-marked coin were found from the lower levels. According to Gupta (1996:22), copper punch-marked coins are found from the post-Mauryan period from the Magadh-Anga, Mathura, and Mewar regions. Thus, on the basis of all the evidence taken together, we have dated the deposits in this excavated northwestern area of Indor Khera from about 200 B.C. to A.D. 300.

\section{Structures}

Walls in all cases were oriented in the cardinal directions. These were constructed both of mud-bricks as well as burnt bricks. It is possible to recognize that these walls were constructed in different phases, which will be discussed shortly. Structures were traced in B1a, B1b, B1c, B1d, C1a, A1d, B2b, and B2c.

Walls/structures of two phases were found in B1a. Belonging to a later phase (Phase II) were two east-west-oriented walls, $242 \mathrm{~cm}$ apart, composed of mudbricks (Walls 11 and 12). The well-preserved mud-bricks varied in size from 38$42 \mathrm{~cm}$ in length, 22-24 cm in width, and 5-6 cm in thickness. The extant length of Wall 11 was $200 \mathrm{~cm}$ while that of Wall 12 was $176 \mathrm{~cm}$. Wall 11 is better preserved and comprised of eight courses, while in the case of Wall 12 about four courses were clearly discernible. Walls were raised with courses of header bricks, making the width of Wall 12 about 38-42 cm. Under the mud-brick courses of Wall 11 is a facing of mud-bricks, below which are two courses of baked bricks. Between these two walls was detected a paved platform $(105 \mathrm{~cm}$ east-west $\times 110$ $\mathrm{cm}$ north-south) on a mud-brick base. On excavating farther down between Walls 11 and 12 an ashy patch that can be seen in Figure 3 was found. Both Walls 11 and 12 meet up in the east with a north-south-oriented baked brick wall (Wall 13). This latter wall appears to have been built in an earlier phase (Phase I), which continued to be used into the later phase. The width of Wall 13 is unknown as it goes into the west-facing section of the subsquare. However, the excavated remains show a double row of stretcher bricks making the extant width at least $80 \mathrm{~cm}$. Wall 13 runs through the entire length of subsquare B1a and part of B1d. The sizes of the baked bricks vary from $36-44 \mathrm{~cm}$ in length, $22-24 \mathrm{~cm}$ in width, and $5-6 \mathrm{~cm}$ in thickness. The bricks in the northeastern part of B1a abutting Wall 11 also reveal remains of a mud plaster.

Projecting courses of baked bricks (Wall 14), varying in size from $38-42 \mathrm{~cm}$ in length, 22-24 cm in width, and 5-6 cm in thickness, were recovered below Wall 12. These appear to be part of a Phase I structure, which extends southward from subsquare $\mathrm{B} 1 \mathrm{a}$ into the northern part of $\mathrm{B} 1 \mathrm{~d}$. About $70 \mathrm{~cm}$ south of these projecting courses of baked bricks is another baked brick alignment of header bricks (Wall 15) extending eastward into Wall 13 found in B1a. These bricks had dimensions of $40 \times 22-24 \times 5-6 \mathrm{~cm}$ (Fig. 3). Nine courses of bricks were recovered with headers and stretchers in alternate courses. The area of $70 \mathrm{~cm}$ between Walls 14 and 15 was filled with a packing of mud and brickbats. In the northern part of B1b, burnt brickbats laid flat were recovered covering an area of about $120 \times 180 \mathrm{~cm}$. These appear like a brick paved area or platform belonging to Phase I.

In the center of B1d was excavated a paved platform (measuring $118 \mathrm{~cm}$ north-south $\times 70 \mathrm{~cm}$ east-west) of Phase II with thick mortar underneath which 


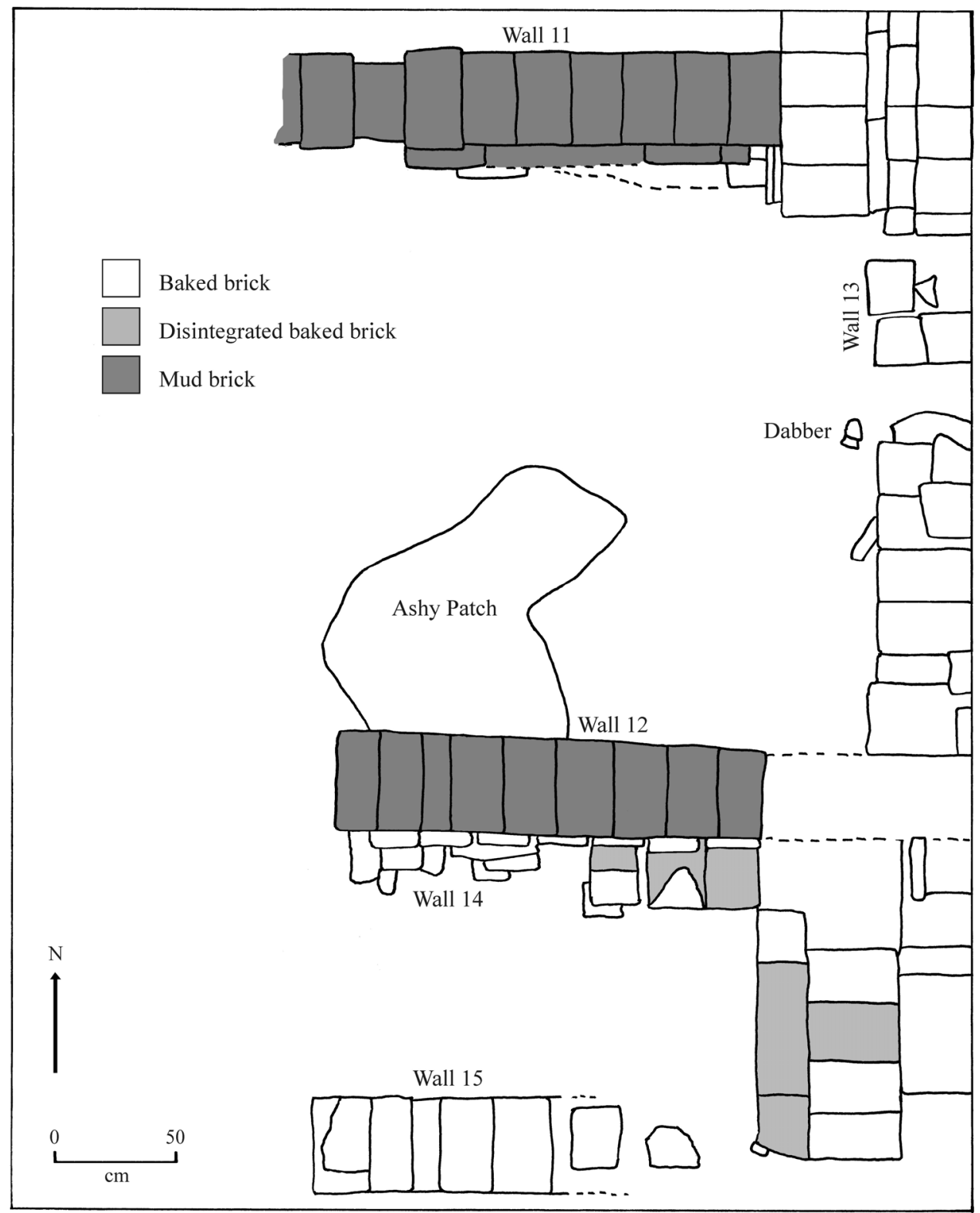

Fig. 3. Plan of House 1 at Indor Khera.

there were mud-bricks. To its north was an ashy patch measuring $118 \mathrm{~cm}$ northsouth $\times 170 \mathrm{~cm}$ east-west. Almost the entire area of the rest of subsquare B1d was comprised of a loose gray deposit. In B1c and B1d were recovered walls of several phases. Belonging to Phase III was an east-west-oriented wall (Wall 10) of baked header bricks, with dimensions of $42 \times 24 \times 5-6 \mathrm{~cm}$. Wall 10 extended $538 \mathrm{~cm}$ in length with a width of $42 \mathrm{~cm}$. In some places two courses were recovered, while in others three courses of bricks could be discerned. Wall 7 is a Phase IV, east-west-oriented wall of baked bricks. It is conjectured that Wall 7 with 
four courses of header bricks may have had a length of $534 \mathrm{~cm}$ and a width of 22 $\mathrm{cm}$. One intact brick in the western end of subsquare B1d was noted to have dimensions of $38 \times 22 \times 5-6 \mathrm{~cm}$. Two parallel north-south walls (Walls 8 and 9), $300 \mathrm{~cm}$ apart, extended southward from this east-west wall, perhaps forming a room. Of these, the western wall, Wall $8,224 \mathrm{~cm}$ in length, extended south to the end of the subsquare, while of the eastern wall (Wall 9), only three bricks were extant. The end of Wall 9 was not discernible as it was cut by a wall from a later period (Phase V), an east-west baked brick wall (Wall 1) in B1c. Of the three bricks, one was marked by four grooves in an arc formed perhaps by the fingers, to enable better jointing of bricks. Wall 1 measured $230 \times 40-42 \mathrm{~cm}$. Of this wall 17 courses were extant. The wall was constructed with header bricks with dimensions of $38-42 \times 22-24 \times 5-6 \mathrm{~cm}$.

In C1a were excavated two baked brick walls (Walls 2 and 3), one oriented north-south and the other oriented east-west, with the two meeting at right angles, perhaps comprising part of a room. The width of the walls is about 40 $\mathrm{cm}$. The length of Wall 3 in C1a is $200 \mathrm{~cm}$ while that of Wall 2 extended over the length of the subsquare. The brick sizes varied from $38-40 \mathrm{~cm}$ in length, $22-24 \mathrm{~cm}$ in width, and $5-6 \mathrm{~cm}$ in thickness. Six courses of header bricks in Wall 2 were recovered below which was a light brown compact deposit. Five courses of header bricks were recovered of Wall 3. To the east of Wall 2 was excavated a baked brick and brickbat platform that extended the length of the subsquare and had an extant width of $164 \mathrm{~cm}$. The walls in C1a belong to Phase $\mathrm{V}$.

In A1d, an east-west wall (Wall 4), made of yellow-colored mud-bricks was found, of which only a few bricks were clearly visible but traces of the wall were found both west and east through the entire length of $4 \mathrm{~m}$. Wall 4 , belonging to Phase $V$, was raised of header bricks with dimensions of $36 \times 24 \times 5-6 \mathrm{~cm}$. Abutting Wall 4 toward the southwest were traces of a yellowish compact deposit perhaps representing a paved platform, of which the surviving portion measured $90 \times 48 \times 5-6 \mathrm{~cm}$ of now disintegrated mud-bricks.

$\mathrm{B} 2 \mathrm{~b}$ was opened up to investigate whether the walls recovered in B1a extended westward. The same burning activity that was visible in the northwestern corner of B1a with alternate lenses of gray ash and black charcoal was seen to continue in the southeastern corner of B2b. A baked brick alignment of $90 \times 24$ $\mathrm{cm}$ of five courses (Wall 5), belonging to Phase V and oriented in an east-west direction, was found in the northeastern corner. Several fallen bricks were found to the south of this structure. A north-south-oriented brickbat alignment (Wall 6), belonging to Phase $\mathrm{V}$, of $30 \times 70 \mathrm{~cm}$, was found in the northern part of B2c.

Thus five phases of structural activities were discerned in this area. To the first phase, Phase I, belonged Walls 13, 14, and 15. Our reading is that perhaps Wall 13 , with a width of at least $80 \mathrm{~cm}$, is part of the remains of a fortification wall. Walls 14 and 15 with their brickbat and mud packing appear to be cross-walls abutting Wall 13. What have been excavated are the upper levels of the fortifications. The fortification wall and cross-walls were probably built before 200 B.C. The deposits that we have excavated probably date to a phase when expansion led to occupations just outside the fortification walls. This explains the construction of mud-brick Walls 11 and 12 of Phase II, which were built against Wall 13 . These two walls represent part of a house (House 1), probably a room, with dimensions of $240 \times 200 \mathrm{~cm}$. The deposits within this room were excavated and 
recorded separately and will be discussed below. Wall 10 belongs to Phase III. To Phase IV belong Walls 7, 8, and 9, which again form a room of a house (House 2). This room measured $300 \mathrm{~cm}$ and at least $240 \mathrm{~cm}$. A compact yellow deposit probably represents traces of a mud floor. To Phase $\mathrm{V}$ belong Walls 1-6. Of these, Walls 2 and 3 are part of a room of a house (House 3), with dimensions of at least $276 \times 200 \mathrm{~cm}$.

\section{Terracotta Finds}

A number of terracotta artifacts of a variety of types were recovered. These have been tabulated in Table 1. As mentioned above, artifacts found within a room of

Table i. Quantification of Terracotta Finds from Excavations in the Northwestern Part of Indor Khera

\begin{tabular}{|c|c|c|}
\hline MATERIAL & OBJECT & COUNT \\
\hline \multirow[t]{33}{*}{ Terracotta } & Bead & 11 \\
\hline & Arecanut bead & 28 \\
\hline & Unfinished bead & 3 \\
\hline & Bangle fragment & 6 \\
\hline & Button & 3 \\
\hline & Disc & 15 \\
\hline & Plaque & 1 \\
\hline & Small vessel & 3 \\
\hline & Reel & 5 \\
\hline & Shuttle & 1 \\
\hline & Stamp & 2 \\
\hline & Dabber & 4 \\
\hline & Coil & 4 \\
\hline & Lump & 4 \\
\hline & Human figurine & 6 \\
\hline & Animal figurine & \\
\hline & Bull & 7 \\
\hline & Horse & 1 \\
\hline & Humped animal with teats & 1 \\
\hline & Marble & 24 \\
\hline & Wheel & 15 \\
\hline & Toy cart & 1 \\
\hline & Perforated object & 10 \\
\hline & Potsherd disc & 59 \\
\hline & Unidentified & 11 \\
\hline & Handmade objects (possibly made by children): & \\
\hline & Miniature rounded object & 1 \\
\hline & Miniature bowl on stand & 1 \\
\hline & Miniature bowl & 18 \\
\hline & Miniature dish & 2 \\
\hline & Miniature box & 1 \\
\hline & Miniature cylinder & 1 \\
\hline & Unfinished miniature vessel & 13 \\
\hline \multirow[t]{3}{*}{ Clay } & Handmade objects (possibly made by children): & \\
\hline & Miniature perforated object & 1 \\
\hline & Miniature lump & 1 \\
\hline
\end{tabular}


Table 2. Quantification of Terracotta Finds from within House i at Indor KHERA

\begin{tabular}{|c|c|c|}
\hline MATERIAL & OBJECT & COUNT \\
\hline \multirow[t]{8}{*}{ Terracotta } & Arecanut bead & 1 \\
\hline & Pendant & 1 \\
\hline & Figurine (possibly animal) & 1 \\
\hline & Potsherd disc & 1 \\
\hline & Dabber & 2 \\
\hline & Vitrified lump & 2 \\
\hline & Inscribed lid & 1 \\
\hline & $\begin{array}{l}\text { Handmade object (possibly made by children): } \\
\text { Unfinished miniature vessel }\end{array}$ & 5 \\
\hline
\end{tabular}

House 1 were excavated and documented separately and these have been listed in a separate table (Table 2).

The evidence consists of tools such as dabbers and stamps, unfinished objects such as beads, miniature vessels and unfired clay objects, as well as debitage including vitrified lumps and coils of clay. Several terracotta animal figurines were found in this area. These are made by the same technique of hand modeling. The bull figurines were fired in reducing conditions while the horse and the humped animal with teats were oxidized. The finds of numerous animal figurines suggests that these were made here. While the animal and human figurines were hand modeled, the terracotta plaque, on the other hand, was molded. This represents the face of a woman with part of an elaborate headdress visible. Several of the terracotta artifacts found fall into the category of toys, which may have been made and used here. These include marbles, wheels, and a toy cart, with the latter two categories of artifacts representing miniature replicas that probably reflect the work of skilled adult crafters. Apart from these are other miniature objects, including vessels that appear to have been made by children, which are discussed in detail below.

Although the room in subsquare B1a was excavated and recorded separately, the deposits to its south, in B1d, were contemporary. This explains the similarity of the finds within the room to some of those in Table 1, such as unfinished miniature vessels, dabbers, and vitrified lumps. This suggests that the room in B1a and the area to the south, that is in B1d, were part of a potter's house (House 1). This is also corroborated by the traces of a paved area found in B1d, south of the room as well as a substantial ashy patch suggesting a firing area. The sections in B1d also show multiple episodes of firing reflected in an $88 \mathrm{~cm}$ thick, loose ashy gray deposit with alternating bands or lenses of pink, white, and black. Certain finds within this structure, such as the arecanut bead, terracotta pendant, glass ornaments, iron objects, and copper antimony rod suggest everyday objects, and hence a living cum working area. In the same context can be mentioned the inscribed lid that was recovered, which is unfortunately not legible. The presence of children discussed in the context of Table 1 is evident within this house from the miniature vessels that they were in the process of making but which were left incomplete. 


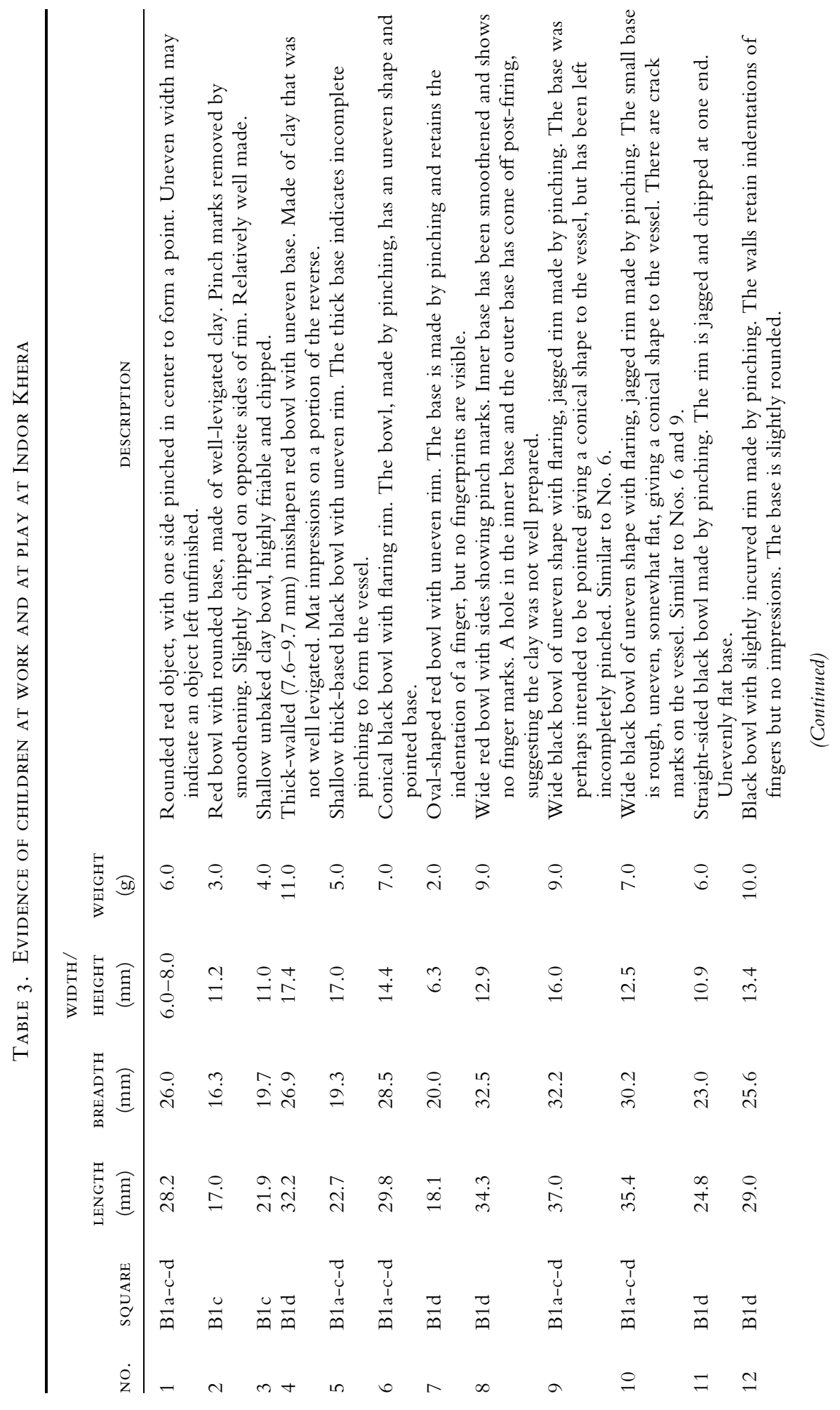




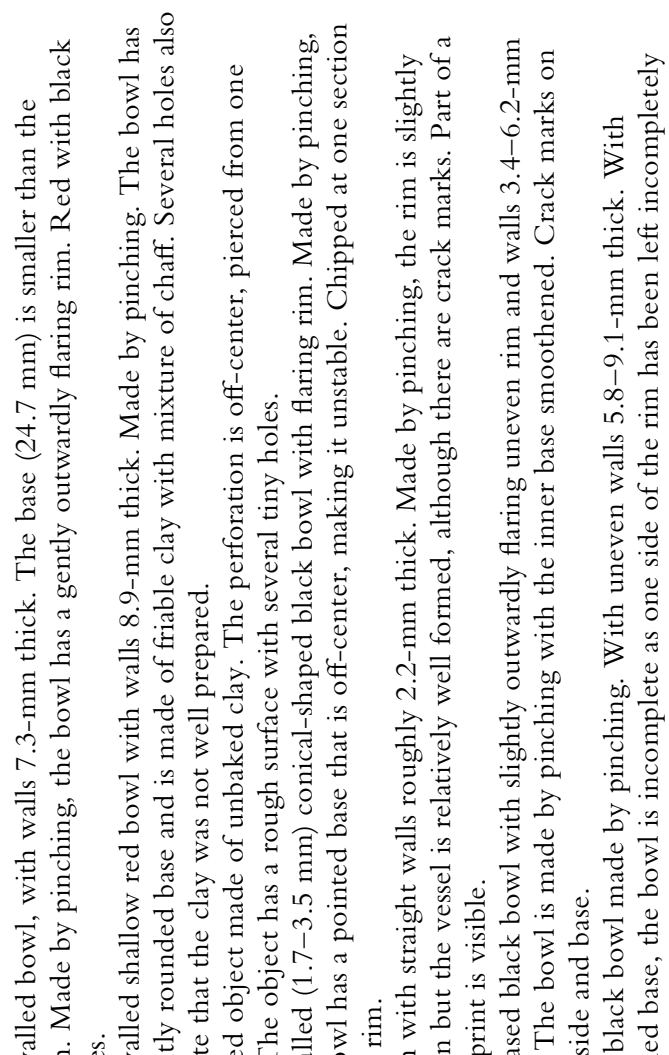

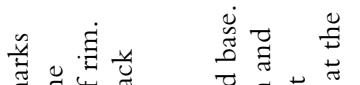

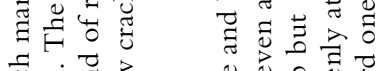

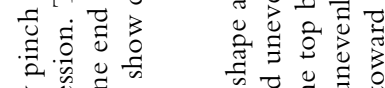

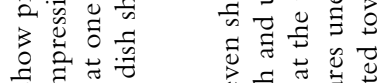

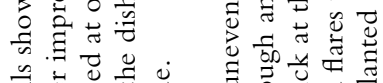

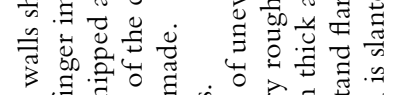

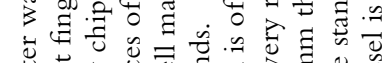

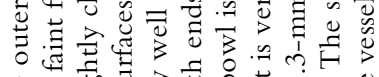
ชั

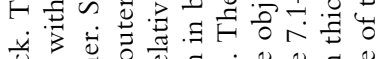

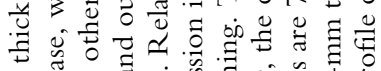

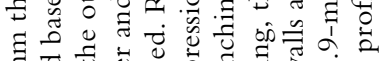

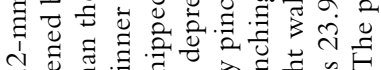

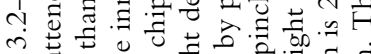

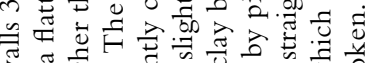

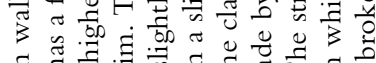

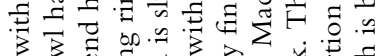

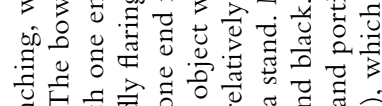

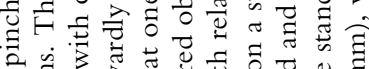

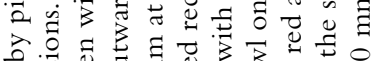
完.

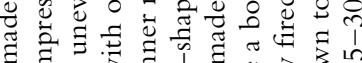

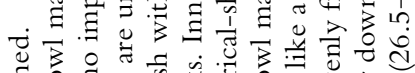

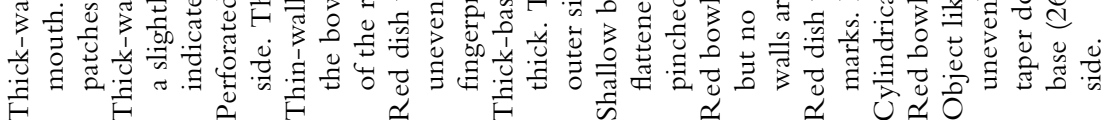

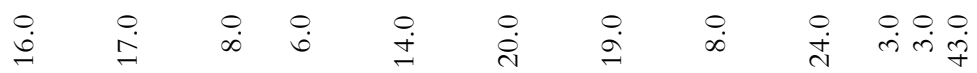

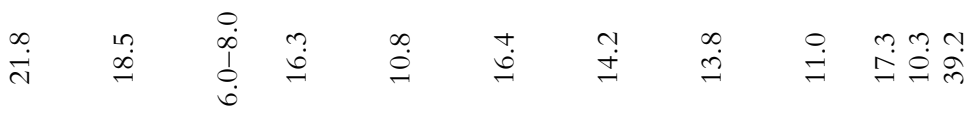

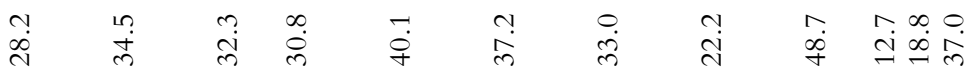

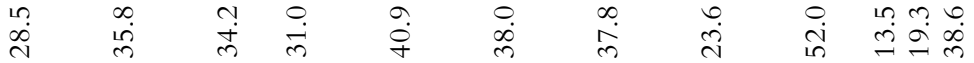

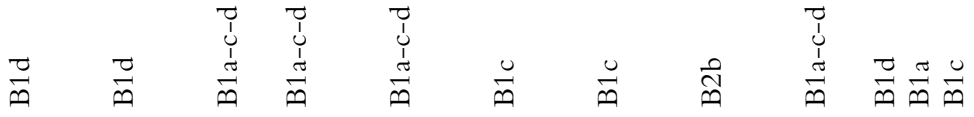

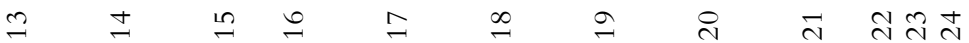




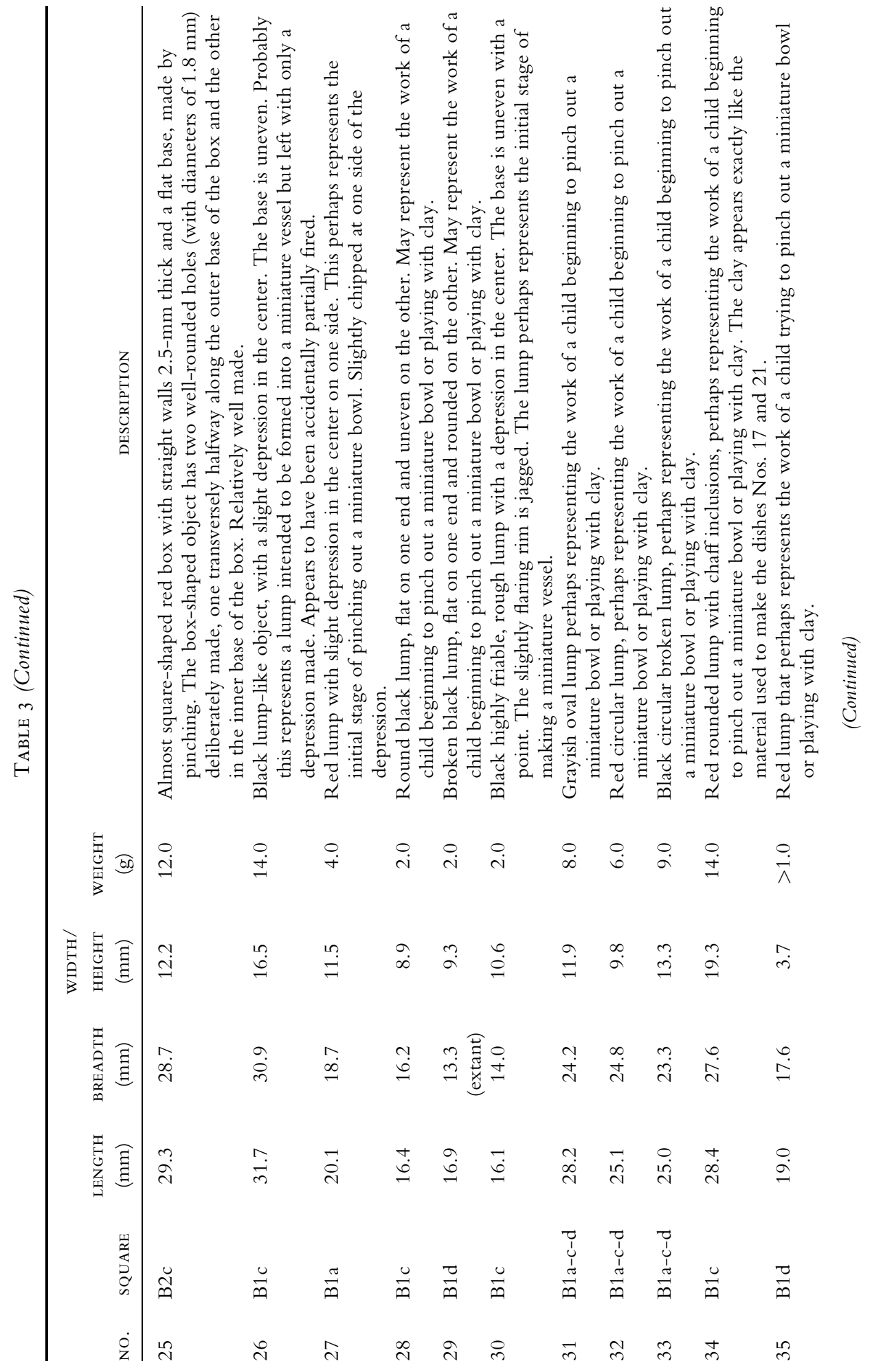




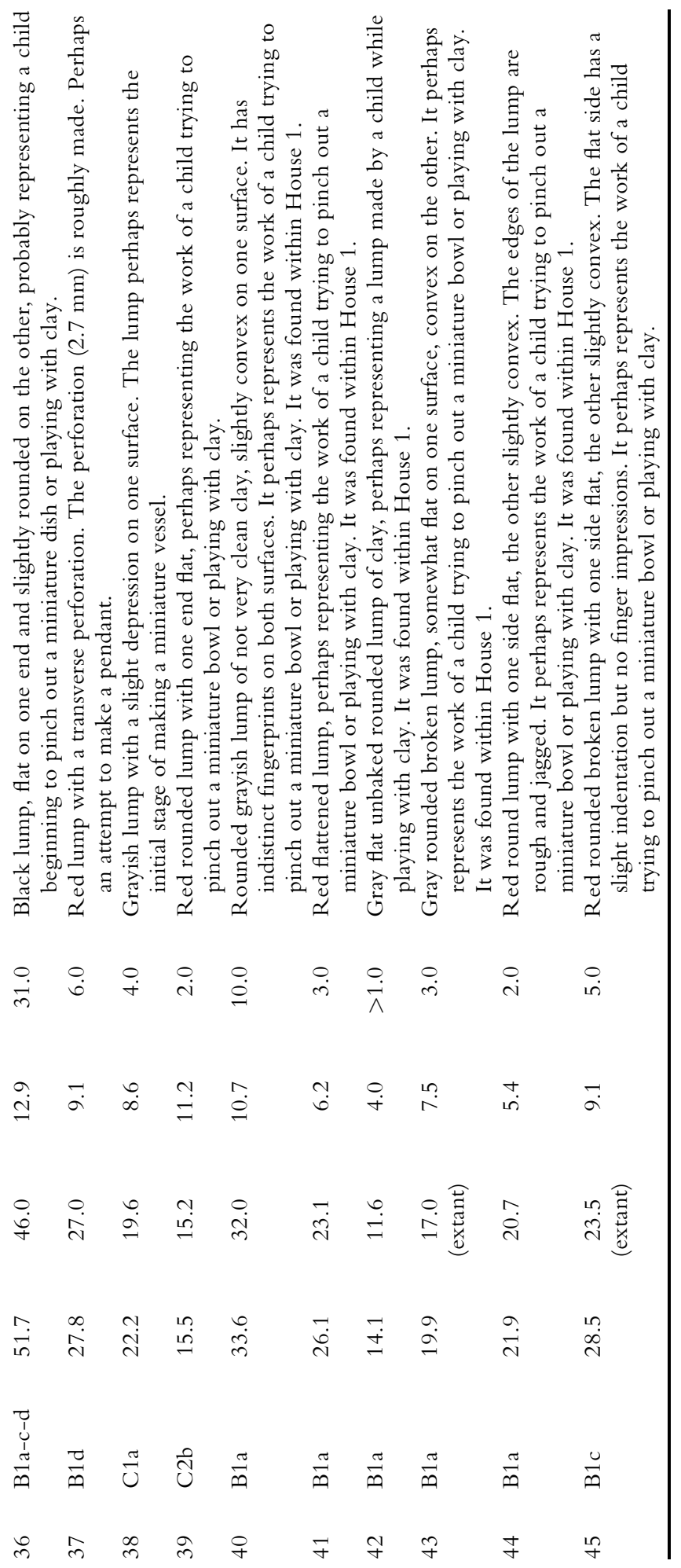




\section{CHILDREN AT WORK AND AT PLAY IN A POTTER'S HOUSE}

The discussion above indicated that there may be several ways of identifying the work of children in ceramics through experimentation, learning, and play. Aspects such as miniature size of products, deficiencies in manufacture (such as inexpert preparation of clay or formation of vessels and objects), and simplicity of techniques may indicate children's activities. Drawing on this kind of evidence, we were able to identify certain artifacts that suggest they were made by children at Indor Khera (Table 3).

It is evident from Table 3 that the vessels are tiny, falling into the miniature category. Out of the 44 items listed in Table 3, 22 are discernible vessels, comprising bowls, dishes, a square box, and a bowl on a stand (Figs. 4-6). Since most of the vessels are not symmetrical, the length and breadth measurements rather than diameter are presented. The majority, 18 in number, are bowls, while the rest comprise two dishes, one square box and one bowl on a stand. The rim diameters of bowls, derived by averaging the length and breadth measurements, range from a maximum of $37.6 \mathrm{~mm}$ to a minimum of $16.6 \mathrm{~mm}$. Similarly, the diameters of the two dishes are $40.5 \mathrm{~mm}$ and $50.3 \mathrm{~mm}$, while the diameter of the bowl on a stand is $37.8 \mathrm{~mm}$. Of the remaining 22, three (Nos. 1, 15, 22) are indeterminate objects while 19 (Nos. 26-44) are lumps probably representing initial stages of making miniature vessels and objects or indicating children playing with clay. Many of these lumps are tiny with measurements ranging from $32.8 \times 10.7$ $\mathrm{mm}$ to $12.8 \times 4.0 \mathrm{~mm}$ (Fig. 7 ).

Central to the identification of children's work has been the issue of size, with miniature forms associated with children. It is well understood that archaeological contexts should provide clues about the functions of artifacts, in this case regarding those that are miniature in size. One such context can be a craft working area wherein miniature forms may have a particular meaning. These miniature ceramic vessels need not necessarily be replicas of full-sized forms. In a learning context, the initiation of a novice who often is a child begins with pinching small pieces of clay into rough shapes. These initial experimental efforts result in forms that are not necessarily mirrored in those produced by adult or expert crafters. As pointed out earlier, this may be due to less developed motor skills or inadequate perceptions of ceramic styles.

As can be seen from Table 3 and Figures 5 and 6, certain miniature vessels (Fig. 6d, Table 3: No. 4; Fig. 5h, Table 3: No. 8) exhibit the use of clay that has not been well prepared. A thick-walled shallow bowl (Fig. 5a, Table 3: No. 14) is a highly friable specimen revealing an excessive admixture of chaff. The majority of vessels are hand-modeled using the pinching technique, which is well known as one of the simplest techniques of shaping ceramics and one used by children beginning to learn the craft. This can be seen from the finger indentations on several examples. However, largely no fingerprints are identifiable. Thus, the kind of analysis undertaken by Kamp (2001b) and Kamp et al. (1999) is not possible at least so far as the miniature vessels recovered at Indor Khera are concerned.

The asymmetrical forms of these miniature vessels are another indicator of child crafters. Several specimens reveal uneven walls such as a thick-walled bowl (Fig. 6d, Table 3: No. 4) from 7.6-9.7 mm, a thin-walled conical shaped bowl (Fig. 5k, Table 3: No. 16) from 1.7-3.5 mm, a thick-based bowl from 3.4-6.2 mm 

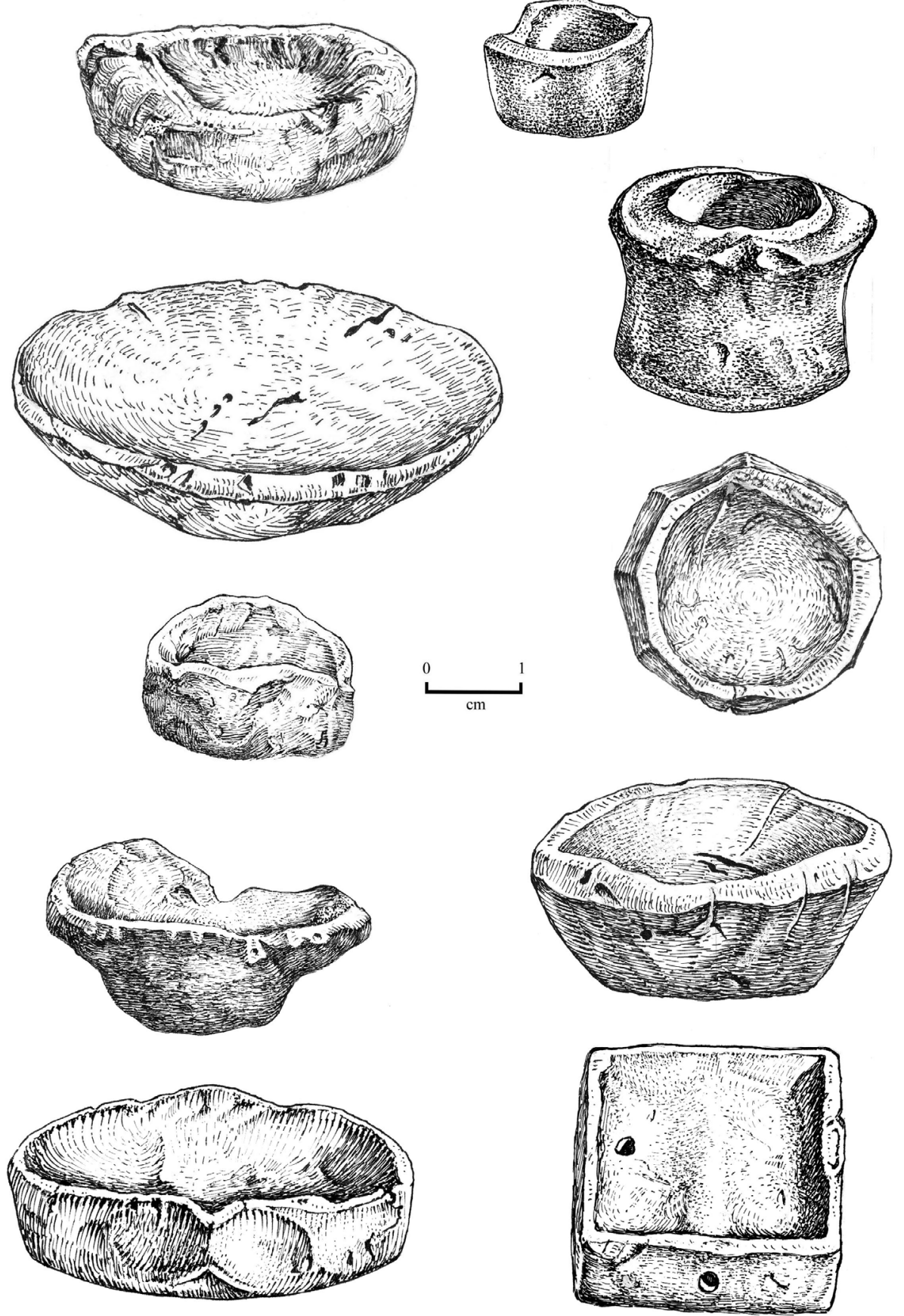

Fig. 4. Variety of miniature vessels made by children at Indor Khera. 

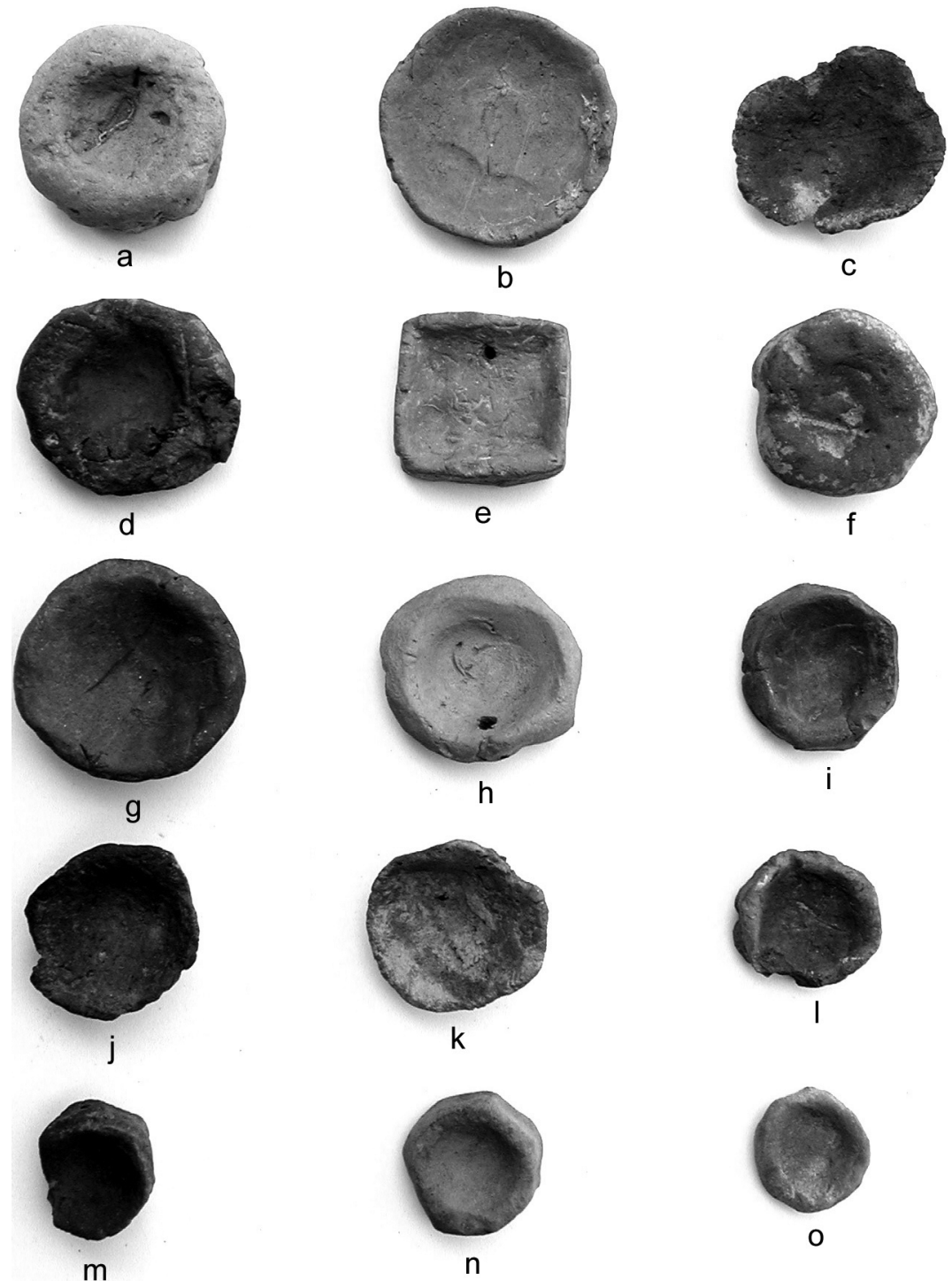

$\mathrm{h}$
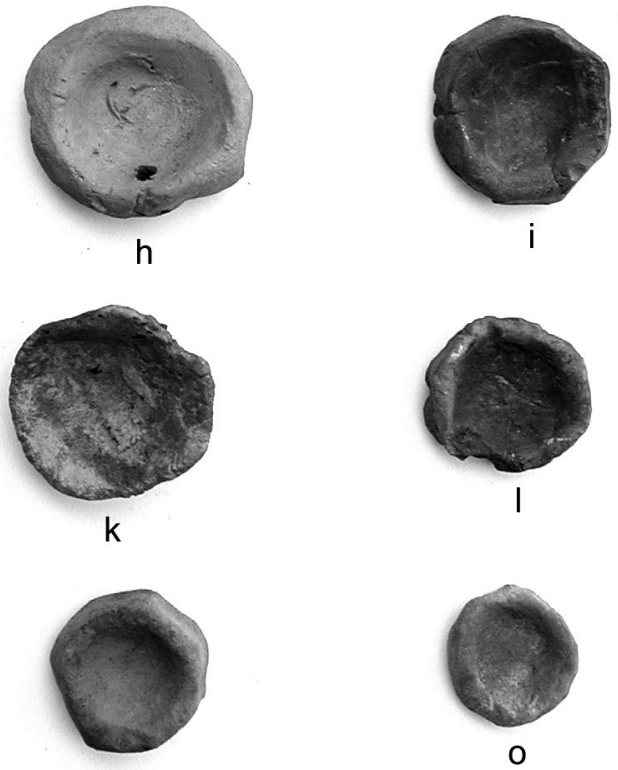

$\mathrm{n}$
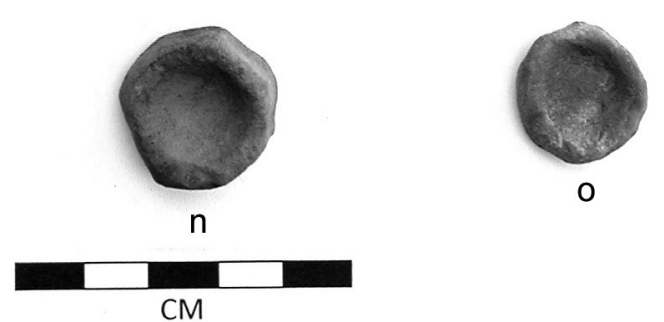

Fig. 5. Efforts of children at Indor Khera to make miniature vessels.

(Fig. 5g, Table 3: No. 18), a shallow bowl (Fig. 5d, Table 3: No. 19) from 5.8$9.1 \mathrm{~mm}$, and the bowl on stand (Table 3: No. 24) with walls ranging from 7.1$8.3 \mathrm{~mm}$. Uneven heights of walls can be seen in a bowl (Fig. 5n, Table 3: No. 20) with one end higher than the other. A number of vessels have thick bases (Fig. 5m, Table 3: No. 5; Fig. 5g, Table 3: No. 18) that suggest a lack of skill in vessel formation. Other vessel bases are unevenly formed (Fig. 6d, Table 3: No. 4; Fig. 5c, Table 3: No. 10; Fig. 5l, Table 3: No. 11; Fig. 6e, Table 3: No. 23) and in some cases are pointed and unstable (Fig. 5j, Table 3: No. 6; Fig. 6c, Table 3: 


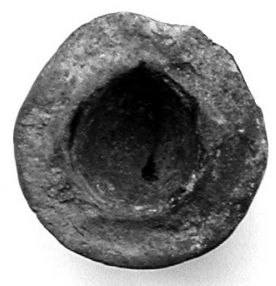

a
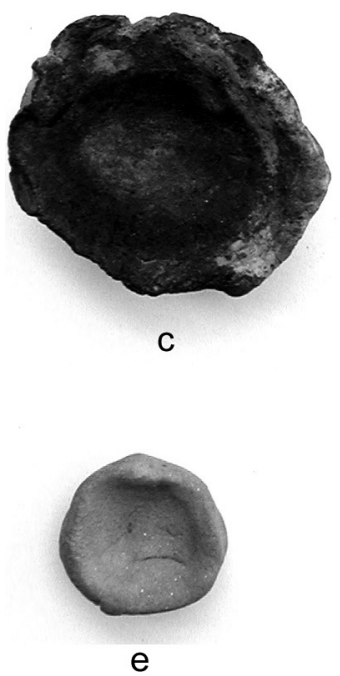

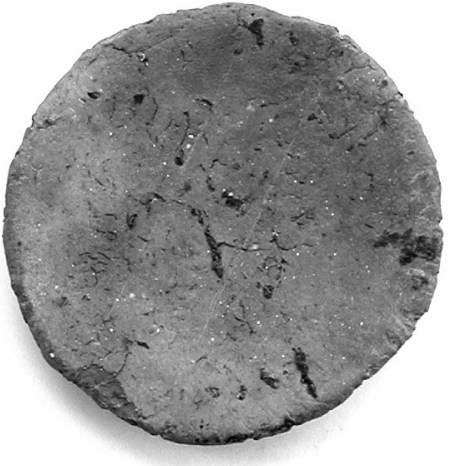

b
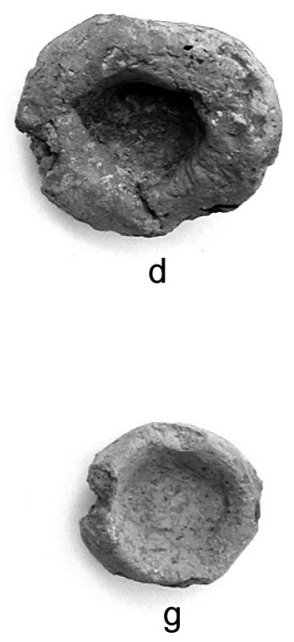

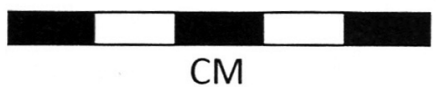

Fig. 6. Range of skills exhibited by children at Indor Khera while making miniature vessels.

No. 9; Fig. 5k, Table 3: No. 16). Inexpertly formed rims resulting in uneven and jagged shapes can be seen in several bowls (Fig. $5 \mathrm{~m}$, Table 3: No. 5; Fig. 5o, Table 3: No. 7; Fig. 6c, Table 3: No. 9; Fig. 5c, Table 3: No. 10; Fig. 51, Table 3: No. 11).

Inadequate drying of miniature vessels has resulted in crack marks that can be observed in a bowl (Fig. 5c, Table 3: No. 10) and both the dishes (Fig. 5b, Table 3: No. 17; Fig. 6b, Table 3: No. 21). As far as firing is concerned, there is an even distribution of vessels fired in oxidized and reduced atmospheres. It is unlikely that children would be firing their own products, but they would have assisted 


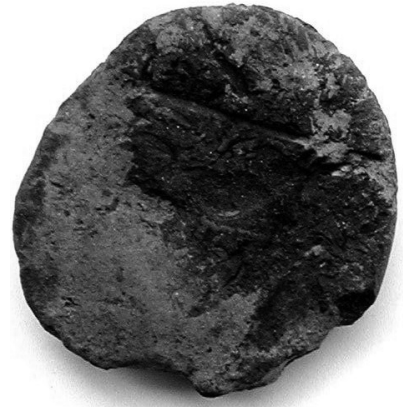

a

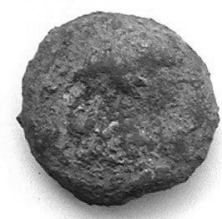

d
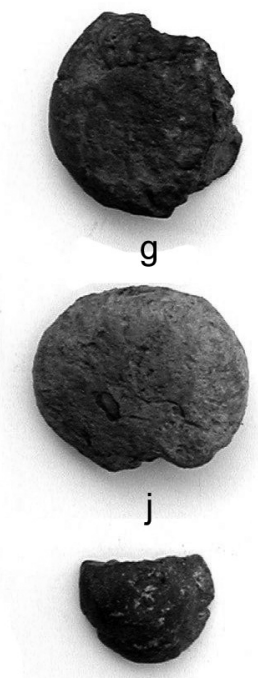

m
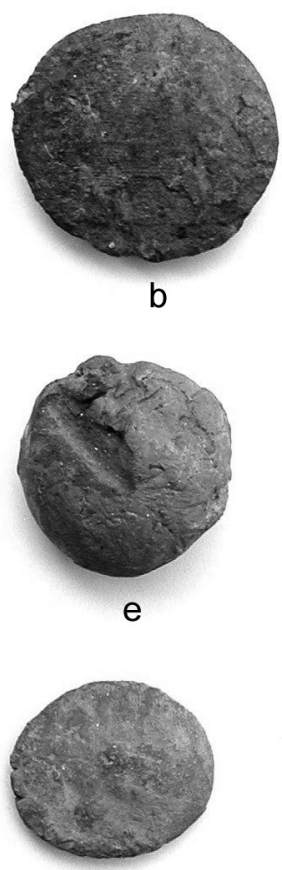

h
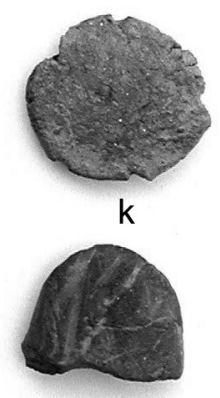

$\mathrm{n}$
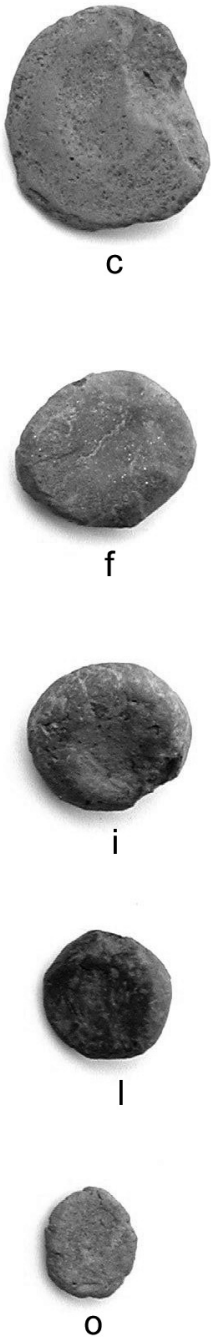

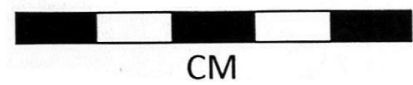

Fig. 7. Terracotta lumps suggesting children at play in Indor Khera.

adults in the process. It appears that not much care had been taken in firing these miniature vessels. Two miniature vessels show black patches on a red background. On the whole, the reduced examples are also friable suggesting inadequate clay preparation and drying, as well as careless firing. A few objects are left unfired such as the perforated object (Table 3: No. 15) made of unbaked clay, with a rough surface and several tiny holes. 
As mentioned earlier, 19 lumps were found that have been suggested to represent initial stages of making vessels and objects. Many of these are circular rounded lumps, having a slight depression in the center, or flat on one surface and unevenly convex on the other. Five such lumps came from House 1. A gray flat unbaked rounded lump of clay (Table 3: No. 42) from House 1 suggests a tiny bit of clay shaped by a child. Thus, given the context of a potter's house, it is possible that children may have been given small bits of clay to play with. These children may also have been watching adults at work as well as assisting them. The learning process would have combined observing, assisting, experimenting, and playing with clay.

Clearly, there are variations in the levels of skill exhibited by these miniature objects. While largely these are roughly made, a few, like the bowl (Fig. $6 f$, Table 3: No. 2), dishes (Fig. 5b, Table 3: No. 17; Fig. 6b, Table 3: No. 21) and the small square box (Fig. 5e, Table 3: No. 25) are relatively better made. These variations suggest a progressive development of skill among child crafters and may reflect age differences. While children as young as two to five years of age could have started playing with clay, the rough shaping of simple vessel forms, such as the small bowls found at Indor Khera, may have been done by children between five and eight years old. It is also significant that the majority of the discernible vessel forms made by children at this ancient site are bowls. This is probably the easiest shape to make using the pinching method and has been ethnographically documented in the subcontinent. The initial stage of working with ceramics for a boy or a girl is the making of an earthen lamp (in form resembling a small bowl). Only after this stage are children initiated into clay preparation. Further learning stages in ceramics appear to be demarcated according to gender, with boys given a small wheel to learn throwing as well as the beating of vessels and girls learning to paint (Saraswati 1979:33). Some of the other tasks associated with the ceramic craft, such as molding, slipping, and polishing, however, do not seem to be gender specific. Thus, it is probable that the miniature vessels and lumps recovered from Indor Khera reflect the work and play of both small boys and girls.

\section{CONCLUSION}

While children as active agents have been visualized in archaeological work outside the Indian subcontinent, such studies are singularly lacking in the case of South Asian archaeology. This is a preliminary study that has tried to locate children within learning frameworks showing them as active producers of material culture. The miniature vessels found in a potter's house indicate the particular spaces that were used by children in ancient Indor Khera. The specific attributes of these miniature vessels such as small size, asymmetrical shapes of largely the single form category of small bowls, with uneven rims, walls, and bases, with drying cracks and uneven firing suggest that these were the work of children, perhaps between five and eight years old. Further, tiny bits of clay could have been given to children, perhaps as young as two to five years of age, to play with as indicated by the find of numerous small lumps, some with depressions and others flattened. Although a few of the relatively better made vessels seem to indicate incremental skills, what are perhaps absent are the intermediate stages between the products of novices and skilled crafters. The latter is an aspect that still remains to be investigated. 


\section{ACKNOWLEDGMENTS}

Kathryn Kamp sent us her articles on children, which have been extremely useful for our work. Mudit Trivedi and Somesh Vishwakarma sent us at very short notice certain articles that we did not have access to. We are grateful to all of them. Narayani Gupta first asked us whether children were visible in Indian archaeology. It was during discussions with $\mathrm{M}$. A. Alvi while he was drawing the miniature artifacts that the idea of these being made by children first came up. Rimli Bhattacharya has been trying to persuade us over several years to collaborate on a children's storybook within an archaeological setting, which still remains to be written. Kumkum Roy's endeavor to write ancient Indian history in more interesting ways for children through the School Textbook Project has also convinced us to think about children. This article owes much to them; however, the lacunae are entirely ours.

\section{ENDNOTES}

1. Our intention is not to provide a comprehensive bibliography of the work done on the archaeology of children but to point out some of the main areas that have been explored. For fuller reviews, see Ardren 2006, Baxter 2005, Baxter 2008, and Kamp 2001 a.

2. Ardren $(2006: 7)$ has pointed out that children's experimental efforts can include the reuse of discarded objects. For example, the reuse of broken potsherds could be indicated through the category of "hopscotches," which are common to several archaeological reports.

\section{REFERENCES CITED}

Ardren, Traci

2006 Setting the table: Why children and childhood are important in an understanding of ancient Mesoamerica, in The Social Experience of Childhood in Ancient Mesoamerica: 3-22, ed. T. Ardren and S. R. Hutson. Boulder: University Press of Colorado.

Ardren, Traci, and Scott R. Hutson, eds.

2006 The Social Experience of Childhood in Ancient Mesoamerica. Boulder: University Press of Colorado.

BAXTER, JANE Eva

2005 The Archaeology of Childhood: Children, Gender, and Material Culture. Walnut Creek, CA: Alta Mira Press.

2008 Archaeology of childhood. Annual Review of Anthropology 37 : 159-175.

BAxter, Jane Eva, ED.

2006 Children in Action: Perspectives on the Archaeology of Childhood. Archaeological Papers of the American Anthropological Association 15. Berkeley: University of California Press.

Clark, Sharri R.

2003 Representing the Indus body: Sex, gender, sexuality, and the anthropomorphic terracotta figurines from Harappa. Asian Perspectives 42(2):304-328.

Gupta, Parmeshwari Lal

1996 Coins. New Delhi: National Book Trust.

Kamp, Kathryn A.

$2001 a$ Where have all the children gone?: The archaeology of childhood. Journal of Archaeological Method and Theory 8(1):1-34.

$2001 b$ Prehistoric children working and playing: A southwestern case study in learning ceramics. Journal of Anthropological Research $57: 427-450$.

2002 Working for a living: Childhood in the prehistoric southwestern Pueblos, in Children in the Prehistoric Puebloan Southwest: 71-89, ed. K. A. Kamp. Salt Lake City: The University of Utah Press.

2006 Dominant discourses; lived experiences: Studying the archaeology of children and childhood, in Children in Action: Perspectives on the Archaeology of Childhood: 115-122, ed. J. E. Baxter. Archaeological Papers of the American Anthropological Association 15. Berkeley: University of California Press.

Kamp, Kathryn A., Nichole Timmerman, Gregg Lind, Jules Graybill, and Ian Natowsky

1999 Discovering childhood: Using fingerprints to find children in the archaeological record. American Antiquity 64(2):309-315. 
LOPIPARO, JEANNE

2006 Crafting children: Materiality, social memory, and the reproduction of Terminal Classic House societies in the Ulua Valley, Honduras, in The Social Experience of Childhood in Ancient Mesoamerica: 133-168, ed. T. Ardren and S. R. Hutson. Boulder: University Press of Colorado.

Menon, Jaya, and Supriya Varma

n.d. Everyday objects, pottery production and non-elite houses in the medieval period at Indor Khera (manuscript in review).

Menon, Jaya, Supriya Varma, Suchi Dayal, and Paru Bal Sidhu

2008 Indor Khera revisited: Excavating a site in the upper Ganga plains. Man and Environment $33(2): 88-98$.

PARK, Robert W.

1998 Size counts: The miniature archaeology of childhood of Inuit society. Antiquity 72(276) : 269-281.

2006 Growing up north: Exploring the archaeology of childhood in the Thule and Dorset cultures of Arctic Canada, in Children in Action: Perspectives on the Archaeology of Childhood: 53-64, ed. J. E. Baxter. Archaeological Papers of the American Anthropological Association 15. Berkeley: University of California Press.

Raczec, Teresa P.

2003 Subsistence strategies and burial rituals: Social practices in the late Deccan chalcolithic. Asian Perspectives 42(2): 247-266.

Roux, Valentine, and Daniela Corbetta

1989 The Potter's Wheel: Craft Specialization and Technical Competence. New Delhi: Oxford \& $\mathrm{IBH}$.

Rye, Owen S., and Clifford Evans

1990 Traditional Pottery Techniques of Pakistan: Field and Laboratory Studies. Smithsonian Contributions to Anthropology 21. Washington, DC: Smithsonian Institution Press.

Saraswati, Baidyanath

1979 Pottery-making Cultures and Indian Civilization. New Delhi: Abhinav Publications.

Smith, Patricia E.

2006 Children and ceramic innovation: A study in the archaeology of children, in Children in Action: Perspectives on the Archaeology of Childhood: 65-76, ed. J. E. Baxter. Archaeological Papers of the American Anthropological Association 15. Berkeley: University of California Press.

VArma, Supriya, and Jaya Menon

n.d. Craft quarters at the edge of a settlement: Indor Khera 200 BCE-300 CE (manuscript in review)

\begin{abstract}
It is only in the recent decade that distinct archaeological studies on children have emerged. One of the ways in which children have been made archaeologically visible has been in the context of craft and learning frameworks where they have been perceived as active agents in the production of material culture. Archaeologically, the work of novice crafters can be discerned through attributes of small size, asymmetrical forms, and other deficiencies in manufacturing techniques suggesting inadequate conceptual frames as well as less developed physical skills. The deposits recovered during the excavations in the northwestern part of the ancient site of Indor Khera have been dated between 200 B.C. and A.D. 300. The excavations have revealed in an early phase a potter's house within and around which several miniature vessels with similar characteristics were found, perhaps the work of children. Further, numerous tiny terracotta and clay lumps indicate that to begin children might have been given small bits of clay to play with. It appears that the ceramic craft may have involved a gradual learning process that included play, observation, and experimentation. KEYwORDS: children, ceramic production, learning, playing, miniature vessels, Indor Khera, Upper Ganga Plains, India.
\end{abstract}

